\title{
Além do Cânon: Mão Invisível, Ordem Natural e Instituições ${ }^{\star}$
}

\author{
- Antonio Tiago loureiro araújo dos Santos* - Ana Maria Bianchi **
}

\begin{abstract}
RESUMO
O artigo propõe um entendimento não canônico da mão invisível de Adam Smith, que implicou uma leitura atenta dos textos originais e sua inserção no contexto histórico e intelectual da época. Para atingir esse objetivo, identificamos a conexão entre mão invisível e noções correlatas (ordem natural, conseqüências não intencionais) e discutimos o deísmo e o papel das instituições no pensamento de Smith. A discussão é precedida por breve apresentação dos fundamentos comportamentais da teoria smithiana, com a qual procuramos melhor amparar nossas conclusões.
\end{abstract}

\section{PalaVRAS-CHAVE}

Adam Smith, mão invisível, conseqüências não intencionais, ordem natural, instituições

\section{ABstract}

The article proposes a non-canonical understanding of Adam Smith's invisible hand, which implied a careful reading of the original texts and their framing in the historical and intelectual context of their time. To reach this goal, we identify the connection between the invisible hand and correlated notions (natural order, non-intentional consequences) and we discuss deism and the role of institutions in Smith's thought. The discussion is preceded by a brief exposition of the behavioral foundations of the Smithian theory, in which we looked for a better support to our conclusions.

\section{KEY WORDS}

Adam Smith, invisible hand, unintended consequences, natural order, institutions

\section{Jel Classification}

$B / 2$

\footnotetext{
+ Uma versão preliminar deste artigo foi apresentada no encontro da Sociedade de Economia Política realizado em Campinas em 2005. Os autores agradecem aos pareceristas anônimos desta revista pelas sugestões de mudança recebidas, que permitiram esclarecer pontos importantes.

* Mestre pelo Instituto de Pesquisas Econômicas da USP e ex-bolsista da FAPESP. Trabalha atualmente na Secretaria do Tesouro Nacional. E-mail: antonio.a.santos@fazenda.gov.br. End. para contato: Ministério da Fazenda - Anexo - $I^{\circ}$ andar, ala A, COGEP/STN. CEP: 70048-900 - Brasília - DF.

** Professora Titular da Faculdade de Economia, Administração e Contabilidade da Universidade de São Paulo. Email: amafbian@usp.br End. para contato: FEA-USP, Av. Prof. Luciano Gualberto, 908. CEP: 05508-010 - Cidade Universitária - São Paulo - SP.

(Recebido em julho de 2005. Aceito para publicação em fevereiro de 2007).
} 


\section{INTRODUÇÃO: SMITH DESCANONIZADO}

A mão invisível, expressão difundida a partir da obra de Adam Smith, certamente ocupa posição de destaque na história do pensamento econômico. Trata-se de uma metáfora consagrada na economia, ao mesmo tempo que se afigura fonte de interminável polêmica e controvérsia. Deste modo, parece valer a pena realizar um exame mais detido desta noção, segundo proposta que esclareceremos prontamente.

O estudo de um conceito e de um autor de mais de duzentos anos não é, por certo, empreendimento livre de dificuldades e armadilhas. A distância de seu contexto histórico e intelectual não é pequena, seus textos não são mais (via de regra) sistematicamente lidos na formação-padrão do economista atual; e, mais do que isso, há uma imagem recebida do mesmo cristalizada nos cânones da ciência que, mesmo não sendo rejeitável em bloco, certamente constitui obstáculo adicional na aproximação e entendimento das idéias originais do autor.

O conceito de cânon (Bianchi e Nunes, 2002), que pretendemos enfatizar nesta introdução, traz importantes idéias sobre o que buscamos aqui desenvolver. Basicamente, "cânon" pode ser entendido como padrão ou regra, ou ainda como lista ou catálogo. O conceito deixa transparecer importante carga religiosa ou mitológica, instância em que os autores canonizados desempenham o papel de heróis do passado, exemplos a serem imitados. No entanto, "[u]ma vez instituido, o cânon perde sua temporalidade. Em outras palavras, ele liga o presente ao passado de forma unilinear, essencialmente distorcida." (ibid p. 162). O autor canonizado fala diretamente ao presente, o que em si não é problema, posto que clássicos constituem fonte permanente de sabedoria. ${ }^{1}$ A questão é que o autor é descolado de seu tempo, sua voz é descontextualizada, quando não seu pensamento é enquadrado em esquemas teóricos contemporâneos estranhos ao autor original, porém familiares - e, portanto, facilitadores - ao economista moderno.

Reconhecido o problema, torna-se importante descanonizar a interpretação padrão, de modo a reconstituir a pluralidade de vozes presentes no discurso do passado e o ambiente em que foi proferido. Trata-se de enfatizar os escritos originais, para promover sua análise a partir do contexto histórico e intelectual em que foram gerados.

Ora, o conceito de cânon também sugere um problema correlato: o que é dito por um autor não corresponde, muitas vezes, à percepção ou interpretação de seus leitores, que é a versão cristalizada na sabedoria recebida. A percepção de Smith como advogado do egoísmo e da ganância, num contexto de laissez-faire estrito, bem como de portador de um otimismo panglossiano, certamente constitui uma caricatura grosseira (Fonseca,

1 Pelo menos em uma visão soft science, em que a teoria econômica se constrói com os clássicos, como bem argumenta Arida (1984). 
1993; Sen, 1987), como fica evidente a qualquer um que se disponha a estudar sua obra com seriedade. No entanto, embora Smith jamais tenha defendido o egoísmo sem freios, ou mesmo acreditado na inevitabilidade de um final feliz para a humanidade, deve haver motivos para que esta visão tenha sido consagrada nos cânones da economia. A chave da questão pode estar, da mesma forma, no entendimento do contexto histórico e intelectual no qual Smith escreveu, tendo sua mensagem sido "apropriada" por divulgadores e panfletários da maneira que julgassem mais conveniente, segundo interesses da época por eles esposados.

A popularidade da Riqueza das Naçôes (daqui por diante, $W N$ ) foi imensa já de imediato, tendo sido objeto de diversas edições e traduções em várias línguas. Independentemente de polêmicas infindáveis sobre a paternidade da economia política como um todo, ou mesmo sobre a paternidade desta ou daquela idéia particular, é inegável que a obra conferiu ao saber econômico status acadêmico, sistematicidade e abrangência inéditas, além de ter despertado o interesse tanto de homens práticos como daqueles mais interessados em questóes de teoria abstrata. (Cardoso, 2002). Trata-se, de fato, de obra que lança um paradigma, no sentido kuhniano de uma realização exemplar, posto que todos os economistas importantes posteriores a ela se referem e a tomam como ponto de partida. (Brown, 1994; Cerqueira, 2003; Ganem 2000; Nunes, 1995). Assim, não surpreende que a $W N$ tenha recebido diversas leituras distintas, o que exprime a própria vocação de um texto clássico.

Por conta disso, a obra de Smith tem sofrido profundo processo de reavaliação e reinterpretação, em especial desde as comemorações do bicentenário da $W N$. É justamente o esforço de isolar a mensagem da obra mediante a contextualização e a leitura cuidadosa do original que pretendemos realizar neste texto, em torno particularmente da idéia de mão invisível, tão cara ao pensamento smithiano, tão impactante e, ao mesmo tempo, tão polêmica dentro do pensamento econômico e social posterior.

Para cumprir esse objetivo, cabe primeiramente retomar alguns elementos importantes do pensamento de Smith. Começaremos por discorrer (muito) brevemente sobre seus "fundamentos comportamentais", expostos principalmente em sua obra A Teoria dos Sentimentos Morais (daqui por diante, TMS), publicada pela primeira vez em 1759. Este aspecto de seu pensamento tende a ser relativamente negligenciado, apesar de ser crucial para um entendimento mais abalizado da dinâmica por trás da figura da mão invisível. Disposto este pano de fundo, procederemos ao núcleo do artigo, que consiste na análise textual das três ocorrências da expressão "mão invisível" na obra smithiana. Cada uma dessas ocorrências suscita questôes e problemas distintos, que serão analisados pari passu. Como preparação para esta discussão, abordaremos a questão de uma economia mercantil descentralizada. Após discutir cada caso da mão invisível, abordaremos o tema correlato das consequiências não intencionais da ação 
humana. Na conclusão, a partir de uma breve discussão sobre os processos históricos e intelectuais subjacentes à constituição da economia como disciplina científica, pretendemos explorar, com relação à mão invisível, as noções de ordem natural e o papel das instituições, sobre o pano de fundo de um jogo entre otimismo e ceticismo no pensamento de Smith.

\section{FUNDAMENTOS COMPORTAMENTAIS}

\section{i. A Formação dos Juizos Morais}

É amplamente sabido que Adam Smith foi professor de filosofia moral, curso que abrangia desde teologia natural e ética propriamente dita até jurisprudência e economia política. (Raphael e Macfie, 1976). Posto que, para Smith, a economia política era parte da filosofia moral, não surpreende que tenha se tornado consensual na literatura especializada a necessidade de ler sua TMS como requisito para uma visão mais rica de seu pensamento. Somamo-nos assim ao esforço de Cerqueira e Ganem, entre outros, no sentido de buscar a fundamentação filosófica dos pressupostos que orientam a análise mais propriamente econômica de Smith.

A TMS trata de uma gama enorme de assuntos, dos quais, por limitações de espaço e de escopo, nos interessa destacar dois: (i) o processo de formação dos juízos morais; e (ii) a análise do auto-interesse. No tocante ao primeiro ponto, há de se notar que a ética smithiana não é de fácil classificação dentro da dicotomia tradicional de ética deontológica e ética teleológica. Sua teoria moral contém uma explicação de como as pessoas efetivamente, na vida prática, formam noções de moralidade, e como, com base nestas, avaliam moralmente as mais diversas situações. Neste aspecto, trata-se de uma teoria ética empírica, que focaliza como as pessoas, na experiência da vida em sociedade, incorporam sentidos de moralidade. Não é uma ética exortativa a priori, como deve ficar claro ao final desta seção. ${ }^{2}$

O conceito central da teoria moral de Smith é a idéia de simpatia (TMS I.i.l), ${ }^{3}$ que consiste basicamente na capacidade que cada um tem, por imaginação, de se colocar no lugar e na situação de outra pessoa. Assim, por exemplo, se uma pessoa for vítima de má-fé ou de violência, podemos simpatizar (sentir junto) com seu ressentimento, ao mesmo tempo que não podemos simpatizar com a motivação nociva do agressor. Desta forma, a partir da consonância ou não entre os nossos sentimentos e aqueles

2 Naturalmente, a filosofia moral smithiana é aqui apresentada de forma bastante simplificada; um tratamento mais abrangente pode ser encontrado em Raphael e MacFie (1976).

3 Utilizamos aqui a referência-padrão das edições Glasgow das obras completas de Smith. 
das pessoas envolvidas na querela em questão (quer sejam agentes ativos, passivos, ou meros espectadores), podemos avaliar em que medida uma ação foi apropriada (proper) dado seu contexto. (TMS I.i.3.1). Os padrões morais pelos quais julgamos não são impostos de maneira "exógena", nem tampouco decorrem de ditames ou mandamentos da racionalidade; são, ao contrário, fruto deste jogo de espelhos resultante do exercício da simpatia em sociedade, ao longo do tempo. Inicialmente observamos como as pessoas em geral reagem a certos tipos de ação, o que assimilamos prontamente; enfim, o exercício de captar os sentimentos de outras pessoas nos leva tanto a apreender padrões morais como a aplicá-los. (TMS III.4.8).

É verdade, contudo, que as pessoas podem não ser tão cândidas e isentas em seus julgamentos; dito de outra forma, todas estão sujeitas a vieses e partidos os mais diversos, que podem contaminar seus juízos morais. No entendimento de Smith, um julgamento isento e consciente seria aquele proferido por uma pessoa bem-informada e neutra em relação às demais pessoas envolvidas. Posto isto, Smith evoca a figura de um espectador imparcial idealizado, também chamado de "homem dentro do peito", ou "razão", "consciência", que atenderia a estes requisitos para um juízo moral adequado. (TMS III.2.32; além de III.3.4). O espectador imparcial forma seus juízos a partir dos reflexos de sua imagem no conjunto de espelhos em que se mira. A experiência e a observação em sociedade ensinam cada um a julgar com razoável neutralidade o conteúdo moral de diversas situações de sua vida, com um grau tolerável de proximidade do que seria o juízo do espectador imparcial.

Também é interessante notar a comparação de Smith entre justiça e beneficência, ${ }^{4}$ ponto que reflete de maneira bastante interessante o Zeitgeist em sua ruptura com a moralidade medieval. ${ }^{5} \mathrm{O}$ autor argumenta que a "sociedade pode subsistir, embora não no estado mais confortável, sem beneficência, mas a prevalência de injustiça deve destruila completamente." (TMS II.ii.3.3, grifos nossos). ${ }^{6}$ A justiça afigura-se desta forma como o "pilar principal" da sociedade, sem o qual a mesma "deve em um momento se desmoronar em átomos." (TMS II.ii.3.4). A beneficência, por sua vez, "é o ornamento que embeleza, não a fundação que apóia o edifício" de modo que é suficiente recomendála, mas desnecessário impô-la. (Ibid). ${ }^{7}$ Ou seja, embora a vida em sociedade seja bem

4 Cabe observar que Smith (TMS VI.ii.3.1) distingue beneficência de benevolência: a primeira se refere a bons ofícios (ações), a segunda se refere a boa vontade (desejos).

5 A questão da "revolução moral" faz parte de um longo processo, relatado por autores como Cardoso (2002), Hirschman (1977), Bianchi (1988) e Belluzzo (1980). Este ponto será retomado mais adiante.

6 Todas as traduções do inglês são nossas, sendo que incorporamos algumas sugestôes de um dos pareceristas anônimos da revista. Em casos de dúvida, optamos por incluir a expressão inglesa entre parênteses ao lado de sua tradução.

7 Smith estabelece uma distinção clara entre justiça e beneficência. Justiça pode ser exigida à força, beneficência não; a violação da justiça expóe à punição, a falta de beneficência não (embora possa ser desaprovada); a observância da justiça não merece recompensa (pois apenas abstém-se de causar mal a outrem; no máximo, respeitar-se-á a inocência do indivíduo justo), já um grande exercício de beneficência merece grande recompensa. (TMS ii.1.3 e 4 e 9). 
mais agradável onde houver a virtude cristã da beneficência entre seus habitantes, o exercício de tal virtude não é indispensável à vida em sociedade, papel que cabe à observância das regras formais da justiça.

Esta brevíssima apresentação da teoria moral smithiana, bastante parcial e incompleta, tem por objetivo primordialmente servir de subsídio para uma análise mais refinada das variações do auto-interesse na obra smithiana, na seção que se segue, que por sua vez servirá de base à análise posterior da mão invisível.

\section{ii. O Auto-interesse e seus Variantes}

Muito embora o auto-interesse (self-interest) seja o principal conceito comportamental por trás da teoria econômica da Riqueza das Naçôes, ele encontra sua análise mais completa na TMS. É importante mencionar inicialmente que auto-interesse não é, para Smith, sinônimo de egoísmo. Argumentaremos aqui que se trata de um conceito sutil e complexo, com múltiplas variantes, como defendem Ganem (2000), Hollander (1977) e Skinner (1992), entre outros autores.

O ponto de partida da análise se dá com o conceito de amor-próprio (self-love), bastante utilizado entre os filósofos éticos britânicos. ${ }^{8}$ De fato, para Smith, tal conceito insere-se em uma concepção filosófica da natureza humana, oriunda do estoicismo grego:

"De acordo com Zenão, o fundador da doutrina estóica, cada animal foi por natureza recomendado a seu próprio cuidado, e foi dotado com o princípio do amor-próprio, pelo qual ele deve se empenhar em preservar, não apenas sua existência, mas todas as diferentes partes de sua natureza, no melhor e mais perfeito estado de que for capaz."(TMS VII. ii.1.15).

Referindo-se ainda a Zenão, Smith afirma que o "amor-próprio do homem abraçava, por assim dizer, seu corpo e todos seus diferentes membros, sua mente e todas suas diferentes faculdades e poderes." (TMS VII.ii.1.16). Neste sentido, tudo aquilo que pudesse auxiliar o homem a manter-se nas melhores condições possíveis seria desejado, ao mesmo tempo que se rejeitaria tudo que pudesse ter efeitos destrutivos. Não apenas saúde e vigor, mas também "riqueza, poder, honra, o respeito e a estima daqueles com os quais vivemos" apresentam-se como características desejáveis; enquanto fraqueza e doença, além de "pobreza, falta de autoridade, desprezo ou ódio daqueles com os quais vivemos", são características a serem evitadas. (Ibid).

8 Tradição à qual Smith de fato pertenceu, juntamente com seu amigo Hume e seu professor Hutcheson, além de Shaftesbury, Butler e Ferguson, entre outros. V. a essse respeito Raphael e MacFie (1976). 
Pode-se daí depreender uma faceta relevante do amor-próprio: embora natural ao homem, não se apresenta como algo rígido. Muito pelo contrário, o amor-próprio é multifacetado, não se resume a um instinto de sobrevivência e autopreservação física, mas projeta-se na esfera social em seus âmbitos moral, político e econômico. Ao expor sua própria doutrina, Smith claramente reflete esta concepção estóica de amor-próprio:

"Cada homem é, sem dúvida, por natureza, primeira e principalmente
recomendado a seu próprio cuidado; e como ele é mais apto para cuidar
de si do que de qualquer outra pessoa, é adequado e correto que assim o
seja. Cada homem, portanto, é muito mais profundamente interessado
no que quer que imediatamente lhe diga respeito, do que naquilo que diz
respeito a qualquer outro homem." (TMS II.ii.2.1).

Neste trecho, Smith menciona a recomendação do amor-próprio (que é cuidar de si) e a associa à idéia de interesse: o indivíduo precisar cuidar de si, logo cria interesse no que diretamente lhe diz respeito. Desta maneira, na prática as noções de amor-próprio e auto-interesse são equivalentes. ${ }^{9}$

Temos, portanto, uma definição genérica de auto-interesse. Esta noção é entendida como natural ao homem, embora seja suficientemente ampla para abrigar uma série de variações em grau e direção. Uma destas variações é o egoísmo, que é como Smith chama o auto-interesse "excessivo" ou "deturpado". De fato, Smith usa egoísmo "mum sentido pejorativo para tal amor-próprio que incorra em dano ou negligência de outras pessoas." (Raphael e Macfie, 1976, p. 22; Ganem, 2000). Veremos que a distinção entre auto-interesse e egoísmo depende fortemente de uma compreensão prévia da filosofia moral smithiana. De fato, esta distinção embute uma importante conexão entre as teorias ética e econômica de Smith, posto que, nas diversas passagens em que trata do tema, Smith sistematicamente observa que este auto-interesse exacerbado obtém de imediato condenação moral por parte da sociedade, como veremos abaixo.

Smith (TMS II.ii.2.1) afirma que entregar-se, à custa de outras pessoas, à "preferência natural que cada homem tem por sua própria felicidade acima da felicidade de outras pessoas", é algo que nenhum espectador imparcial pode aceitar. ${ }^{10}$ Se ele quiser que o

9 A equivalência entre auto-interesse e amor-próprio é endossada por Skinner (1992, p. 149) e Raphael e MacFie (1976, p. 21-2), e pode-se perceber que Smith usa estes termos indiferentemente em trechos como (TMS I.i.2.1) e (TMS VII.ii.3.12).

10 Cabe neste ponto inserir um complemento à breve exposição que fizemos previamente da teoria moral de Smith: a "preferência natural" que cada pessoa tem sobre sua felicidade acima da felicidade de outras pessoas decorre do fato óbvio de que, por mais que sejamos capazes de simpatizar com os sentimentos de outras pessoas, nunca podemos sentir o que elas sentem com a mesma vivacidade que elas ou, mais propriamente, com a mesma vivacidade que sentimos nossos sentimentos; e tão mais fraca é nossa simpatia quanto mais distante for a pessoa do nosso ciclo de convívio. Daí a possibilidade de nosso amor-próprio descarrilar para um sentimento exacerbado e egoista. 
espectador imparcial simpatize com os motivos de sua conduta, que de todas as coisas é a que ele tem o maior desejo, ele deve abaixar a arrogância de seu amor-próprio, até o nível ao qual os outros possam aceitar. ${ }^{11}$ Os espectadores irão até o ponto de permitir-lhe perseguir sua própria felicidade com mais assiduidade que a de qualquer outro homem, pois, colocando-se em seu lugar, podem simpatizar com seus motivos:

"Na corrida por riqueza, honras, e vantagens, ele pode correr tanto
quanto puder, e estirar cada nervo e cada músculo, de modo a passar à
frente de todos seus competidores. Mas se acotovelar, ou derrubar algum
deles, a indulgéncia dos espectadores chega inteiramente ao fim. É uma
violação do jogo limpo, que eles não podem admitir." (Ibid).

Assim, quando uma ação humana tem efeitos previsíveis sobre a felicidade de outros, a voz do espectador imparcial vem lembrá-lo de que ele é apenas um na multidão, em nenhum aspecto melhor que os outros, e que "quando preferimos a nós mesmos tão vergonhosa e cegamente aos outros, nos tornamos os objetos próprios de ressentimento, ódio e execração." (TMS III.3.4). Segue-se que as "deturpações naturais do amor-próprio podem ser corrigidas apenas pelo olho do espectador imparcial.” (Ibid). Em outras palavras, apenas pelo testemunho do espectador imparcial pode-se fazer qualquer comparação apropriada entre nossos próprios interesses e aqueles de outras pessoas. (TMS III.3.1).

Desta forma, podemos constatar que o egoísmo é uma conjunção de auto-interesse forte e simpatia fraca (com relação a pessoas distantes e sem relações com o agente), que não deixa de despertar execração social quando foge a certos limites.

Como pequeno detour, é digno de nota que Smith abra a sua TMS justamente com uma rejeição do egoísmo universal: "Por mais egoísta que se suponba o homem, há evidentemente alguns principios em sua natureza que o interessam na sorte (fortune) de outros, e tornam sua felicidade necessária a ele, embora ele não derive nada disto a não ser o prazer de vê-la.” (TMS I.i.1.1). Isto porque as pessoas têm sentimentos naturais e, mais do que isso, têm a capacidade de se colocar no lugar de outras pessoas, como Smith se apressa em dizer em seguida, ao introduzir a noção de simpatia.

Como vimos, o egoísmo é alvo de imediata condenação moral. Quanto ao auto-interesse em geral, como é considerado este motivo, do ponto de vista moral? Neste sentido Smith afasta-se tanto de Hutcheson quanto de Mandeville: para o primeiro,

11 A necessidade de "diminuir o tom" dos nossos sentimentos para o nível ao qual as outras pessoas possam nos acompanhar no sentimento também decorre da simpatia nunca ser perfeita, conforme observado na nota anterior. Já a vontade sincera de que os espectadores simpatizem com nossa conduta advém de outro traço da natureza humana, que Smith chama de vontade de agradar e aversão a desagradar nossa companhia, que é um traço da vida em sociedade que leva a que as pessoas avaliem moralmente sua própria conduta da mesma forma que avaliam a de outras pessoas, por meio de um troca "inversa" de posiçôes e a partir da norma que seria socialmente aceita por um espectador imparcial. 
o amor-próprio nunca pode ser virtuoso (TMS VII.ii.3.12); para o segundo, ele é sempre vicioso. (TMS VII.ii.4.8).

Em contraposição à concepção de Hutcheson, Smith (VII.ii.3.16) observa que a consideração que uma pessoa tem por sua própria felicidade e por seus interesses privados é freqüentemente um princípio elogiável de ação. Os hábitos de economia, diligência, discrição, atenção e aplicação de pensamento, que são supostamente cultivados a partir do auto-interesse, são objeto de estima e aprovação geral. Seria muito duro para o homem, cuja existência tanto depende de objetos externos, se estes sentimentos não pudessem nunca ser considerados virtuosos. (VII.ii.3.17). ${ }^{12}$ Com efeito, Smith reconhece um tipo de virtude que tem como base o auto-interesse, a saber, a prudência:

\section{"O cuidado da saúde, da fortuna [material], do posto [social] e reputação do individuo, dos objetos sobre os quais seu conforto e felicidade nesta vida supõe-se principalmente depender, é considerado como atividade própria daquela virtude comumente chamada prudência." (TMS VI.i.5).}

Os métodos que a prudência recomenda para o aumento de fortuna são aqueles que não expõem ao risco: "conbecimento real e habilidade em nosso negócio ou profissão, assiduidade e diligência no exercício da mesma, frugalidade, e mesmo algum grau de parcimônia, em todas nossas despesas." (TMS VI.i.6). Para adquirir uma boa reputação no exercício de sua profissão, o homem prudente confia na solidez de seus conhecimentos e habilidades (TMS VI.i.7); é sempre sincero e tem horror a se expor à desgraça de se ver pego em mentira. (TMS VI.i.8).

Apesar de bastante respeitável, porém, a prudência não é considerada a mais nobre das virtudes, sendo, portanto, objeto de uma "fria estima", e não de um amor ardente. (TMS VI.i.14). De fato, do ponto de vista filosófico, Smith nem mesmo considera a prudência como a virtude mais importante. Para ele (TMS III.3.35), o homem de perfeita virtude seria aquele que combina o mais perfeito autocomando sobre seus sentimentos egoístas à mais acentuada sensibilidade pelos sentimentos dos outros. Não obstante, porém, a ambição, dentro dos limites da prudência e da justiça, é sempre admirada. (TMS III.6.7).

Em suma, vimos até aqui que o amor-próprio pode ser entendido como uma característica da natureza humana. Como tal, é bastante genérico, e pode desencadear resultados bem diferentes: irrefreado, pode degenerar em egoísmo vicioso; bem orientado, pode converter-se na virtude da prudência.

$12 \mathrm{O}$ fato de o auto-interesse poder ser um motivo elogiável de ação também tem a ver com a revolução moral em curso na época, ponto que retomaremos adiante. A polêmica de Smith com Mandeville também será retomada em momento oportuno. 
Como nota Hirschman (1977), a categoria "interesse" emerge na história das idéias como algo a meio termo da dicotomia tradicional entre paixões e razão, no sentido em que passa a representar certas categorias de paixões não destrutivas, mediadas por razão ponderada. Inicialmente um conceito bastante abrangente, identificado com "interesses gerais", o conceito passa gradualmente a identificar-se com interesse econômico e material, no sentido estrito. Em Smith, como vimos, o conceito é prima facie bastante abrangente, embora adquira conotação mais econômica em $W N$, como seria de esperar. Não obstante, na TMS já há um discussão sobre a motivação da "busca por riquezas", sobre a qual Smith de fato tem visão bastante cética, enquanto filósofo (TMS I.iii.2.1). Por outro lado, o auto-interesse não se converte necessariamente em dedicação ao trabalho, pelo menos no caso do aprendiz e do escravo, pois, em situações que envolvem instituições como a escravidão ou as corporações de ofício, o auto-interesse não gera estímulos para um comportamento diligente: ${ }^{13}$

\section{"Uma pessoa que não pode adquirir propriedade, não pode ter outro inte- resse além de comer tanto quanto [puder], e trabalhar tão pouco quanto possivel. Qualquer trabalho que ele faça além do que é suficiente para adquirir sua própria manutenção pode ser espremido dele por violência apenas, e não por qualquer interesse seu." (WN III.ii.9).}

Embora haja muito ainda a ser explorado acerca do tratamento que Smith dá aos fundamentos comportamentais da natureza humana (Santos, 2002), basta, para nossos propósitos, manter em mente o caráter abrangente e variável do auto-interesse, em particular naquilo que o diferencia do egoísmo.

\section{A MÃO INVISÍVEL: VARIAÇOEES SOBRE UM TEMA}

É intrigante que uma expressão que tenha ocorrido apenas uma vez em $W N$, e mesmo assim já da metade para o fim de suas quase mil páginas, e somente duas outras vezes na obra completa de Smith (uma na TMS, outra no ensaio póstumo sobre a História da Astronomia), tenha exercido tamanho impacto sobre a história do pensamento econômico.

13 Este aspecto tem a ver com o "institucionalismo" de Smith apontado por Rosenberg (1960) e Hollander (1977), entre outros, um ponto importante mas sobre o qual não nos aprofundaremos neste trabalho. Segundo Rosenberg (1960, p. 557), "Smith está constantemente esquadrinhando o impacto de formas institucionais especificas sobre o ator humano. Dada sua concepção básica das motivações e propensões humanas, os tipos especificos de comportamento que podemos esperar de qualquer individuo dependerão da maneira como as instituiçôes ao redor dele estão estruturadas, pois estas determinam as alternativas abertas a ele e estabelecem o sistema de recompensas e puniçôes dentro do qual ele é compelido a operar." 
Muitas seriam as possíveis razões deste impacto, pode-se especular. O sucesso e a autoridade do tratado econômico de Smith podem ser uma dessas razóes, outra poderia ser o caráter eminentemente otimista contido na metáfora, tão afeito ao Iluminismo da época e ao espírito do capitalismo então em franca expansão. Mais ainda, a despeito do reduzido número de ocorrências explícitas da expressão na obra de Smith, o tipo de raciocínio subjacente à mão invisível era bastante comum não só em Smith ${ }^{14}$ como em toda a filosofia de sua época, a ponto de ter se tornado um verdadeiro clichê no século XVIII. (Rothschild, 1994).

O objetivo desta seção é recuperar o que Smith diz textualmente em cada menção que faz à mão invisível. Antes de fazê-lo, contudo, cabe montar o cenário no qual a mão invisível opera, de modo a iluminar o tipo de problema para o qual ela fornece resposta.

\section{i. Uma Economia Mercantil}

Adam Smith abre sua Investigação sobre a Natureza e as Causas da Riqueza das Nações com um capítulo sobre a divisão do trabalho. Ele esclarece que o aumento de produtividade acarretado pela especialização está por trás daquela "opulência universal que se estende até as camadas mais baixas do povo." (WN I.i.10). Em outras palavras, a divisão do trabalho é o fundamento último da riqueza das nações - justamente o tema cujas causas pretende investigar. No entanto, o reverso da moeda é que, "sem a assistência e cooperação de muitos milhares, a pessoa mais humilde em um pais civilizado não poderia ser provida mesmo de acordo com o quê, muito falsamente, imaginamos ser a maneira muito fácil e simples pela qual ela é comumente acomodada." (WN I.i.l1).

Sobre esta questão, Coase (1977) observa que:

"Adam Smith estava certo ao insistir na importância da divisão do trabalho e nós erramos ao desprezá-la, pois ela torna a economia um estudo do homem em sociedade e propõe uma questão extremamente difícil: como é efetivada a cooperação deste vasto número de pessoas em paises ao redor de todo o mundo, que é necessária mesmo para um modesto padrão de vida? A resposta de Adam Smith é que isso é feito por meio do comércio ou da troca, o uso do mercado alimentado pelo auto-interesse." (1977, p. 287).

14 A despeito do reduzido número de ocorrências textuais em sua obra, é fácil inferir casos "implícitos" da mão invisível no pensamento de Smith, como o surgimento de regras morais de conduta na TMS ou mesmo o próprio surgimento do mercado, que não foi designado por nenhum indivíduo em particular mas cujo resultado final é benéfico à sociedade, visto que as pessoas podem obter na troca mais bens do que se tentassem elas mesmas produzir tudo sozinhas. Este ponto será retomado na sequência. 
Ao mesmo tempo que reformula o problema colocado por Smith, Coase dá uma resposta que, embora compatível com o texto de Smith, não aparece explicitamente no mesmo. Sua resposta, que se tornou canônica na economia, merece qualificação. Em particular, é muito freqüente associá-la ao famoso trecho:

"Não é da benevolência do açougueiro, do cervejeiro, ou do padeiro que esperamos nosso jantar, mas de sua consideração a seu próprio interesse. Nos dirigimos não a seu sentimento de humanidade mas sim a seu amor-próprio, e nunca falamos a eles de nossas necessidades mas sim de suas vantagens. Ninguém salvo um mendigo escolhe depender primordialmente da benevolência de seus concidadãos. Mesmo um mendigo não depende dela inteiramente. A caridade de pessoas bem dispostas, de fato, o aprovisiona com o fundo total de sua subsistência. Mas (...) [c]om o dinheiro que um homem the da ele compra comida. As roupas velhas que alguém the concede ele troca por outras roupas velhas que lhe servem melhor, ou por abrigo, ou por comida, ou por dinbeiro, com o qual ele pode comprar ou comida, ou roupa, ou abrigo, conforme for oportuno (bas occasion).” (WN I.ii.2).

Amartya Sen (1987) faz uma lúcida observação a propósito do trecho em questão. Segundo ele, embora muitos admiradores de Smith não tenham avançado além da passagem citada, a própria leitura da mesma mostra que a preocupação de Smith é especificar porque e como se efetuam as transações normais no mercado e porque e como funciona a divisão do trabalho, tema do capítulo de onde foi extraído o trecho citado. A frequiência com que transações mutuamente vantajosas ocorrem, apontada por Smith, não o leva a defender que o simples amor-próprio, ou, em interpretação mais abrangente, a prudência, garantiriam a existência de uma boa sociedade. De fato, diz Sen (1987, p. 3), Smith defendia exatamente o oposto, pois "não alicerçava a salvação da economia em alguma motivação única."

O capítulo da $W N$ que encerra a famosa passagem recebe justamente o título "Do princípio que dá ocasião à divisão do trabalho", qual seja, a conhecida propensão à troca. Neste capítulo Smith argumenta que por trás desta propensão está efetivamente o auto-interesse, uma vez que cada indivíduo percebe que ao se especializar sua produtividade aumentará a ponto de poder trocar seu produto por muito mais bens do que se ele mesmo tentasse desajeitadamente produzi-los sozinho. Assim, é do interesse de cada indivíduo especializar-se para a troca. Ademais, como bem observa Sen, o capítulo em questão versa sobre "trocas mutuamente vantajosas", ou, como Smith dá a entender, trata-se de "trocas justas e deliberadas", do tipo "isto é meu, aquilo é seu; quero dar isto por aquilo." (WN, I.ii.2). É por isso mesmo que, quando estamos interessados em algo, devemos tentar atrair o interesse de quem está de posse do que queremos. 
Para tanto, há duas formas, diz Smith (ibid): de um lado, a amizade ou adulação; de outro, o oferecimento de algo em troca. Como não temos tempo para ficar adulando os outros cada vez que necessitamos de algo, e como a vida inteira de uma pessoa é curta demais para que ela conquiste um grande número de amizades, ela terá mais chance de obter o que deseja se oferecer algo que interesse à contraparte. (Ibid).

Claro que esta observação, por simples e óbvia que seja, não exclui outros tipos de motivação mesmo na vida econômica; do contrário, o mendigo da história morreria de fome. A observação acima também não implica que a "salvação da economia" resida unicamente no auto-interesse, como deve ficar evidente à luz mesmo de nossa leitura homeopática da TMS. A visão smithiana original por trás do dizer canônico segundo o qual é "o uso do mercado alimentado pelo auto-interesse" que resolve o problema de coordenação (cooperação) de uma economia mercantil descentralizada é bem menos sombria ou cínica do que parece à luz do cânon.

Uma reprise do problema colocado por Coase, porém em roupagem algo peculiar, é aquela formulada por Arrow e Hahn (1971). Para os autores, a resposta "imediata", "de senso comum", à questão de como parecerá uma economia motivada pela ganância individual e controlada por um número muito grande de agentes diferentes é: "Haverá o caos". Já Amartya Sen (1979) coloca um problema distinto, ainda que correlato, ao formular uma questão filosófica que já de longa data perdura no meio intelectual anglo-saxão: "Em que sentido e em que medida o comportamento egoísta atingiria o bem comum?". Ao nos aventurarmos no terreno de uma "ordem espontânea", ou de uma "harmonia de interesses", adentramos mais propriamente o terreno da mão invisível, que agora pretendemos analisar.

\section{ii. A Mão Invisivel na Riqueza das Nações}

A única ocorrência da expressão na $W N$ se dá no segundo capítulo do livro IV, que tem como título "Das restrições sobre a importação de países estrangeiros de tais bens que podem ser produzidos domesticamente”. O trecho em questão, já bastante conhecido, é transcrito abaixo:

"Como cada individuo, portanto, se esforça tanto quanto ele puder seja para empregar seu capital em suporte à indistria doméstica, seja para dirigir aquela indústria de modo que seu produto possa ser do maior valor; cada individuo necessariamente trabalha para tornar a renda anual da sociedade tão grande quanto ele possa. Ele geralmente, de fato, não pretende promover o interesse público, nem sabe o quanto ele o está promovendo. Ao preferir o apoio da induistria doméstica à estrangeira, 
ele pretende apenas sua própria segurança; e ao dirigir aquela indústria de tal maneira que seu produto seja do maior valor, ele pretende apenas seu próprio ganho, e ele é neste, como em muitos outros casos, levado por uma mão invisivel a promover um fim que não eva parte de sua intenção. E nem sempre é pior para a sociedade que não fosse parte dela. Ao perseguir seu próprio interesse ele freqüentemente promove o da sociedade mais efetivamente do que quando ele realmente pretende promovê-lo." (WN IV.ii.9, grifos nossos).

É interessante notar, de partida, que o único uso explícito da mão invisível na $W N$ pouco tem a ver com a idéia de "equilíbrio automático do mercado", que tende a ser sua interpretação canônica. O capítulo em questão está no livro da $W N$ que se dedica à crítica do mercantilismo, em um capítulo que versa sobre comércio externo. Quanto ao argumento concreto da mão invisível, ele trata fundamentalmente de crescimento econômico (pois o resultado é "tornar a renda anual da sociedade tão grande quanto ele possa").

Com efeito, o objetivo de Smith nesta passagem é resumir o argumento desenvolvido ao longo do capítulo. O mecanismo econômico concreto de seu raciocínio tem por objetivo, como já dito, uma explicação do crescimento da renda nacional. Neste contexto, o argumento desenvolvido tem como premissas dois postulados comportamentais: (i) por aversão ao risco, os indivíduos preferem empregar seu capital domesticamente, em vez de no estrangeiro; e (ii) por desejar extrair o maior lucro possível de seu capital, os indivíduos procuram empregá-lo nas indústrias cujo produto seja o de maior valor. Tomando-se o resultado conjunto de (i) e (ii), como cada indivíduo deseja empregar seu capital em seu próprio país e na atividade que lhe dê um produto de valor "máximo", temos que, na soma, o valor do produto do país será correspondentemente maximizado.

Ora, mas onde está o famoso paradoxo da mão invisível? Como bem observado por Cardoso (2002), Smith dissolve aquilo que até então, na história das idéias, fora um paradoxo. A mão invisível é uma variante do argumento mais geral acerca das "consequiências não intencionais" da ação humana. ${ }^{15}$ Argumentos deste tipo foram desenvolvidos por "virtualmente todo autor com contribuição substancial à longa história do pensamento social", de Maquiavel e Vico a Marx e Weber, em uma diversidade de contextos diferentes, da teologia à tecnologia, como aponta Merton (1936). ${ }^{16}$ No entanto, o problema jamais recebera o devido escrutínio pelo fato de ter sempre estado sujeito a "considerações transcendentais". (Ibid). O fato de tais consequiências terem sido

15 De fato, consta do trecho da mão invisível na $W N$ que o indivíduo "não pretende, nem sabe" que promove o bem público.

16 Hayek (1967) ressalta Menger e os filósofos morais britânicos, de importância mais imediata para a economia. 
atribuídas "ao desejo inescrutável de Deus ou Providência ou Destino" tornava dispensável qualquer tratamento científico sistemático. (Ibid). Nas palavras de Hirschman (1977), nunca ficou claro por qual "alquimia" seria efetivamente alcançado o bem comum neste tipo de argumento. Ora, retomando Cardoso, coube a Adam Smith a "tarefa de desenredar as ambigiiidades que continuavam a persistir quanto à melhor maneira de conduzir a análise econômica da relação indivíduo-sociedade." (Grifos no original).

Qual é precisamente a maneira adotada por Smith para dissolver o paradoxo? Ora, o paradoxo estaria resolvido contanto que se apresentasse um mecanismo econômico transparente que explicasse como, exatamente, a busca do interesse individual poderia converter-se no bem comum. No caso do problema tratado acima por Smith, a solução é imediata, pois o interesse comum emerge por simples agregação a partir dos interesses individuais. Como o interesse coletivo é identicamente igual à soma dos interesses individuais, não há paradoxo algum, nem é preciso recorrer a argumentos ad hoc para explicar a compatibilização de interesses.

Pois bem, mas ainda assim o trecho acima pode levar o leitor a levantar alguns questionamentos. Primeiramente, não seria Smith demasiado otimista quando diz que cada indivíduo "necessariamente" trabalha para o crescimento da renda do país? Além disso, não seria o próprio termo "mão invisível" intrinsecamente carregado de significado metafísico, em particular ante o deísmo abundantemente expresso por Smith na TMS $?^{17}$

No que tange à primeira questão, é natural que se considere que cada indivíduo trabalhará para o enriquecimento da nação contanto que ele tenha sucesso em alcançar sua própria meta de enriquecimento pessoal. Como é óbvio, e como relata por diversas vezes na $W N$, Smith reconhece a possibilidade de que indivíduos fracassem economicamente, por imprudência ou mesmo por infortúnio. Além disso, a mão invisível smithiana não significa algo do tipo: "Sob quaisquer circunstâncias e em qualquer caso, a busca dos interesses individuais leva inexoravelmente à realização do bem coletivo." A chave da questão, de fato, é institucional, entendido o conceito de instituição na acepção de North (1990), ou seja, como restrições que definem e delimitam o conjunto de escolhas abertas aos indivíduos. Tudo depende do contexto: em alguns casos, a busca do interesse individual pode ser predatória e prejudicial ao enriquecimento da nação; em outros, pode ser benéfica.

É verdade, como analisaremos mais adiante, que a idéia de "ordem natural" smithiana é razoavelmente otimista, embora Smith guarde sempre certa ambivalência de sentimentos quanto ao progresso econômico, bem como certo ceticismo quanto ao

17 Uma saída interessante da questão, que não exploraremos aqui, é que a mão invisível é uma metáfora, e portanto o que é literalmente dito é diferente do significado que se quer dizer, como aponta Henderson (1994). 
estabelecimento do "sistema de liberdade natural". Essas questôes referentes ao papel das instituições e ao otimismo são importantes e serão retomadas. Por ora, voltemos à segunda questão proposta, que diz respeito ao deísmo de Smith.

A TMS está repleta de menções a um "grande Diretor do universo" que teria feito "a imensa máquina do universo" de modo a produzir "a maior quantidade possivel de felicidade" (TMS VI.ii.3.4), ou ainda, a uma "Providência", que parece muitas vezes se misturar a uma concepção de "Natureza". A credencial deísta de Smith é irrefutável; mas Newton também era religioso, e nem por isso sua teoria foi contestada. (Robbins, 1952). A questão, portanto, não reside no caráter das crenças religiosas de Smith, mas sim em que medida sua argumentação teórica depende de algum elemento "transcendental" para que possa funcionar. Ora, como vimos, o argumento da mão invisível na $W N$ é capaz de ficar de pé por si só, com base em um mecanismo estritamente econômico - não há, portanto, a necessidade de um deus ex machina.

Vale ainda notar, com inspiração em Cardoso, que o processo de emergência da economia política, no qual a $W N$ certamente constitui um marco, é produto da convergência de dois movimentos longos e complexos: a emergência da sociedade mercantil e industrial, e um processo de secularização teórica e ideológica. Com respeito a este segundo processo, a Igreja aos poucos deixa de ser a única lente através da qual se podia examinar o mundo e a natureza humana, que poderiam, em compensação, ser apreendidos racionalmente e por meio da observação empírica. O sucesso das ciências naturais emergentes dá a esperança de se descobrir uma ordem natural também por trás dos assuntos dos homens; e a filosofia do direito natural de fato formula conceitos de "natureza humana" e de "ordem natural social" que posteriormente viriam a influenciar a nascente economia política.

Dessa ótica, o trabalho de Smith pode ser entendido como parte deste processo de secularização; sua teoria prescinde de mediação teológica. De outro lado, dada a complexidade e a longa duração de tais processos, não deve surpreender que haja em Smith abundante linguagem religiosa, ainda que sob roupagem deísta. Em todo o caso, defendemos que sua teoria econômica pode ser entendida em termos laicos, sem a necessidade do intervencionismo divino direto, ou melhor, com uma presença apenas indireta do "grande arquiteto do universo", que monta um cenário com vida e funcionalidade próprias.

Uma interessante evidência adicional a reforçar o caráter laico da mão invisível de Smith pode ser encontrada na própria referência à mão invisível que Smith faz em sua História da Astronomia, como veremos abaixo. 


\section{iii. A Mão Invisível na História da Astronomia}

O uso presumivelmente mais antigo por Smith da expressão "mão invisível" se dá em um ensaio publicado postumamente, intitulado "Os Princípios que direcionam e dirigem (lead and direct) Investigaçóes Filosóficas, ilustrados pela História da Astronomia" (doravante Astronomy). Neste ensaio, em que Smith se pronuncia sobre o conhecimento humano, o autor confere à mão invisível um caráter epistemológico. Comecemos pela concepção smithiana do que é filosofia:

"Filosofia é a ciência dos princípios conectores da natureza. (...). A natureza, após a mais ampla experiência que a observação comum pode adquirir, parece abundar em eventos que parecem solitários e incoerentes com tudo que veio antes deles (...). A filosofia, ao representar as cadeias invisiveis que mantêm juntos todos estes objetos disjuntos, procura introduzir ordem neste caos de aparências dissonantes e discordantes." (Astronomy II.i.2, grifos nossos).

Como se percebe, "filosofia" assume para Smith um caráter bastante abrangente, de explicação científica em geral. Seu objetivo seria encontrar as "cadeias invisíveis" que unem eventos aparentemente desconexos.

Ao referir-se às origens da filosofia, Smith afirma que, nas primeiras eras da sociedade (antes do estabelecimento das leis), o medo e a insegurança dos homens tornavam-nos pouco inclinados a procurar por estas "cadeias escondidas de eventos", de modo a dar ao "teatro da natureza um espetáculo mais conectado para sua imaginação" (Astronomy III.1), muitas "incoerências menores", que são motivo de perplexidade para filósofos, passavam por eles despercebidas. No entanto, "irregularidades magnificentes" tais como cometas, relâmpagos e trovões, incutiam-lhes "terror e consternação". Tais fenômenos eram imputados a "causas inteligentes, embora invisíveis", como descrito no longo trecho abaixo, em que o autor faz referência à mão invisível de Júpiter:

"Com ele [o homem 'primitivo'], portanto, cada objeto da natureza, que por sua beleza ou grandeza, sua utilidade ou nocividade, é suficientemente considerável para atrair sua atenção, e cujas operações não são perfeitamente regulares, é suposto agir pela direção de algum poder designador e invisivel. O mar se distende numa calmaria, ou é içado numa tormenta, de acordo com o bom prazer de Netuno. (...) Dai a origem do politeismo, e da vulgar superstição que atribui todos os eventos irregulares da natureza ao favor ou desprazer de seres inteligentes, embora invisiveis, a deuses, demônios, bruxas, gênios, fadas. Pois pode ser observado que, entre todas as religióes politeistas, entre os selvagens, 
bem como nos primeiros estágios da antigüidade pagã, são apenas os eventos irregulares da natureza que são atribuidos à agência e ao poder de seus deuses. O fogo queima, e a água refresca; corpos pesados descem, e substâncias mais leves voam para cima, pela necessidade de sua própria natureza; nem foi a mão invisivel de Júpiter jamais apreendida como empregada nestas questões. Mas trovão e relâmpago, tempestades e brilho do sol, aqueles eventos mais irregulares, eram atribuidos a seu favor, ou a sua füria. (...) E assim, nas primeiras eras do mundo, a mais baixa e mais pusilànime superstição ocupava o lugar da filosofia." (Astronomy III.2, grifos nossos.)

Já na sociedade "civilizada", com as leis e o estabelecimento da "ordem e segurança", surge a filosofia, aquela "ciência que pretende deixar abertas as conexões ocultas que unem as várias aparências da natureza." (Astronomy III.3). Há menos disposição "para empregar, como cadeia conectora, aqueles seres invisíveis que o medo e a ignorância de seus rudes ancestrais engendraram."

Como observamos anteriormente, a noção de mão invisível vincula-se, aqui, à necessidade de se encontrar uma explicação para certos fenômenos. Para os selvagens politeístas, não há necessidade de explicações ad hoc para o fato de corpos pesados caírem, pois consideram que isso é próprio de sua natureza, como o é também o fato do fogo queimar ou a água refrescar. No entanto, fenômenos mais espetaculares, para os quais não há uma explicação aparente, são atribuídos à mão invisível de Júpiter. De acordo com Smith, a superstição busca explicações na agência de deuses invisíveis, enquanto a filosofia, pelo contrário, busca desenredar a cadeia conectiva invisível de causas explicativas.

É interessante perceber a profusão de instâncias em que o termo “invisível” é utilizado, e os diferentes significados que assume. Em todas essas instâncias, o autor se refere a causas conectoras que não são imediatamente aparentes ou evidentes. No caso da superstição pagã, a cadeia conectora é preenchida pela ação de divindades invisíveis, como é o caso de Júpiter. Por outro lado, a filosofia civilizada buscar descobrir a cadeia de conexão causal que está invisível (i.e., não é imediatamente perceptível). Nesse aspecto, a obra de Smith insere-se no processo de secularização que acabamos de descrever. O autor busca uma explicação filosófica, no sentido de descoberta de cadeias de causalidade, para o fenômeno aparentemente desconexo da busca do auto-interesse como mecanismo de realização do interesse social. Nesse processo, a explicação para todos os fenômenos da natureza, inclusive aqueles que os primitivos atribuíam a Júpiter, torna-se visível. Um raciocínio semelhante é encontrado na $W N$ : como a mão 
invisível pode ser integralmente explicada por meio de argumentos econômicos, ${ }^{18}$ é possível dispensar a intervenção divina como elemento explicativo.

iv. A Mão Invisivel na Teoria dos Sentimentos Morais

A expressão "mão invisível" aparece no capítulo 1 da Parte IV da TMS, intitulado "Do efeito da Utilidade sobre o Sentimento de Aprovação". Transcrevemos abaixo o trecho em questão:

"É em vão que o orgulhoso e insensivel senhor de terras vê seus campos extensivos e, sem um pensamento pelas necessidades de seus semelhantes, em imaginação consome ele mesmo a colbeita inteira que cresce sobre eles. O provérbio caseiro e vulgar, que o olho é maior que a barriga, nunca foi mais plenamente verificado que com respeito a ele. A capacidade de seu estômago não carrega proporção com a imensidade de seus desejos, $e$ receberá não mais do que aquele [o estômago d]o mais humilde camponês. $O$ resto ele é obrigado a distribuir entre aqueles (...) que são empregados na economia doméstica (oeconomy) da grandeza; todos os quais assim derivam de sua luxúria e capricho aquele quinhão das necessidades da vida, que eles em vão teriam esperado de sua humanidade ou justiça. $O$ produto do solo mantém em todos os tempos praticamente o número de habitantes que é capaz de manter. Os ricos (...) consomem pouco mais que os pobres, e apesar de seu natural egoismo e rapinagem, embora eles queiram apenas sua própria conveniência, embora o único fim que eles proponham dos trabalhos dos milhares a quem eles empregam seja a gratificação de seus próprios desejos vãos e insaciáveis, eles dividem com os pobres o produto de todos os seus aprimoramentos. Eles são levados por uma mão invisivel a fazer praticamente a mesma distribuição das necessidades da vida, que teria sido feita tivesse a terra sido dividida em porções iguais entre todos seus habitantes, e assim sem pretendê-lo, sem sabê-lo, avançam o interesse da sociedade, e proporcionam os meios para a multiplicação da espécie. Quando a Providência dividiu a terra entre poucos senhores arrogantes [lordly masters], ela nem esqueceu nem abandonou aqueles que pareciam ter sido deixados fora da partição. Estes ultimos também desfrutam de sua parte em tudo que ela produz. No que constitui a real felicidade da vida humana, eles não são em aspecto algum inferiores àqueles que pareceriam tão acima deles. Em conforto do corpo e paz do espirito, todas as diferentes classes da vida estão aproxi-

18 Há componentes não apenas comportamentais (o auto-interesse, já visto) como também há importante aspecto institucional, conforme teremos a oportunidade de discutir. 


\section{madamente sobre um [mesmo] nivel, e o mendigo, que toma sol à beira da estrada, possui aquela segurança pela qual reis estão lutando." (TMS IV.i.10, grifos nossos).}

Este longo trecho parece, à primeira vista, desmentir tudo o que foi dito até aqui em termos tanto morais como teológicos acerca da mão invisível. Do ponto de vista moral, ao contrário da mão invisível na $W N$, aqui é não o auto-interesse mas sim o egoísmo, a rapinagem, a luxúria e os caprichos, os desejos vãos e insaciáveis (Smith carrega nas tintas) que têm como resultado o bem comum, que, no caso, consiste na distribuição dos frutos da terra para todos. A ironia do argumento é que ele parece recuperar a idéia de "vícios privados, benefícios públicos", de Mandeville, com quem Smith tanto polemiza na TMS (VII.4.12).

Visto que a teoria moral smithiana baseia-se em sentimentos de aprovação ou desaprovação imediata, que se expressam em relação a determinado tipo de conduta, o comportamento egoísta do proprietário de terras seria com toda segurança objeto de desaprovação geral. Não obstante, cabe ressaltar que o capítulo no qual figura este trecho trata do efeito da utilidade ${ }^{19}$ sobre os juízos morais. Neste sentido, o leitor é levado a pensar que o esquema apresentado talvez se mostrasse útil por realizar o propósito de distribuir o produto da terra e proporcionar a "multiplicação da espécie". ${ }^{20}$ O paradoxo, em todo caso, se mantém, pois o bem coletivo é atingido por intermédio de uma motivação socialmente nociva.

A Providência, ademais, é explicitamente trazida à baila. Por mais que esta tenha realizado uma distribuição de terras desigual, o fato de ter designado, por outro lado, estômagos igualmente limitados para todos cuida para que a distribuição do produto da terra seja razoavelmente equânime. Desta forma, a rapinagem do lorde põe em marcha a indústria, à Mandeville, mas seu consumo, diferente de sua ambição, é necessariamente limitado. Ao mesmo tempo, o rico senhor padece de preocupações alheias aos destituídos, de modo que sua felicidade real não é, de fato, superior à dos demais.

Em todo o caso, embora o paradoxo moral seja inescapável, e embora o papel da Providência seja de fato providencial na solução da questão, cabe concluir que, uma vez o cenário tenha sido colocado, o resultado é obtido por forças de dentro do próprio sistema de relações humanas, sem a necessidade de intervenção divina direta. Há

19 "Utilidade" assume em Smith acepção inteiramente diversa daquela do utilitarismo clássico. Seu sentido aproxima-se do uso corrente do termo: diz respeito à adequação de um sistema (ou máquina) para produzir o fim ou resultado para o qual foram criados. (TMS IV.i.2).

20 De toda forma, deve-se ressaltar que a moral smithiana não pode ser enquadrada no utilitarismo conseqüencialista, posição de que Mandeville está mais próximo. 
de se reconhecer, contudo, a homenagem que Smith presta às influências tanto de seu antecessor polemista quanto, notadamente, da tradição deísta.

\section{v. Das Conseqüências Não Intencionais}

Vale a pena, a esta altura, recapitular alguns dos argumentos desenvolvidos até aqui, no tocante à mão invisível de Smith. Sua interpretação canônica, como a "mão invisível dos mercados”, que equilibra automaticamente oferta e demanda, não se sustenta à luz dos três casos textuais da metáfora na obra de Smith. Não obstante, isto não implica que a leitura canônica esteja inteiramente equivocada. De fato, o próprio Smith afirma na WN que o indivíduo "é neste, como em muitos outros casos, levado por uma mão invisível a promover um fim que não era parte de sua intenção." (Grifos nossos). Neste sentido, o próprio Smith aventou a possibilidade de generalização do raciocínio - que na verdade, como já vimos, não era nenhuma novidade em sua época, vide a extensa lista de exemplos coevos deste tipo de raciocínio apresentada por Hirschman (1977).

De fato, o potencial de generalização do princípio é explicitado pela formulação do filósofo político Robert Nozick:

"Um padrão ou estrutura institucional que aparentemente poderia apenas surgir por designio consciente pode, ao invés disso, ser originado ou mantido através das interações de agentes que não têm tal padrão geral em mente. Seguindo Adam Smith, eu nomeei tal processo ou explicação como um processo ou explicação [do tipo] mão invisível." (Nozick, 1994, p. 314).

Em outras palavras, para Nozick a mão invisível é de fato nada mais que um "processo" ou um "artifício explicativo", qualidades que levam a concluir que a mesma pode ser aplicada a um sem-número de situações distintas. $\mathrm{O}$ próprio Nozick trata de enumerar uma série de exemplos que ilustram a generalidade do argumento. Em particular, o próprio equilíbrio de mercado pode ser explicado por um processo do tipo da mão invisível, visto que é um resultado emergente da interação de agentes sem que o mesmo fosse pretendido pelos indivíduos ao realizarem suas atividades particulares de compra e venda. De fato, esta última observação reabilita a interpretação canônica que torna a mão invisível equivalente às forças que ajustam oferta e demanda. Mais especificamente, a mão invisível generalizada de Nozick mostra que o equilíbrio de mercado constitui um caso particular desta classe geral de processos sociais.

Se o equilíbrio é um caso particular da mão invisível, esta constitui, por sua vez, um caso particular de outra classe de fenômenos ainda mais abrangente, a das "conseqüências não intencionais” da ação humana. Por quê? Pelo fato de representar o caso 
em que estas conseqüências são benéficas. Seria, contudo, perfeitamente concebível a ocorrência de consequiências não intencionais de outro tipo: perversas, para tomar de empréstimo o termo utilizado por Hirschman (1992) em contexto algo distinto do nosso.

Com respeito a esse ponto, é interessante a taxonomia de Elster (1984, cap. 1), que reconhece dois tipos de consequiências não intencionais, a saber, aquelas que ocorrem (i) "em adição àquilo que foi pretendido", e aquelas que ocorrem (ii) "ao invés daquilo que foi pretendido." Claramente a mão invisível smithiana recai na primeira categoria: os indivíduos pretendiam enriquecer (e conseguiram), e adicionalmente, como resultado não intencional, o país como um todo enriqueceu. No entanto, é bem plausível que haja conseqüências não intencionais do segundo tipo, que Elster remete ao conceito sartriano de contrafinalidade. ${ }^{21}$

Também é interessante ressaltar que a mão invisível na $W N$ trata de ação individual descentralizada, e não de ação individual organizada; de fato, não existe nenhum objetivo coletivo que oriente a ação dos indivíduos, que é guiada unicamente por interesses pessoais. Esta especificação nos permite distinguir o fenômeno da mão invisível tanto do problema da escolha social de Arrow como do problema da ação coletiva de Olson. Na concepção de Smith, em nenhum momento o "interesse social" é definido como objeto de escolha individual, e tampouco existe a necessidade de organização intencional dos indivíduos para sua consecução. Ademais, há um importante componente agregativo na explicação. Esta importância evidencia-se ao notarmos que se apenas um indivíduo procurar aumentar o valor de seu produto o resultado benéfico da mão invisível não se observará. Na verdade, fenômenos do tipo da mão invisível necessitam de massa, pois tratam de resultados advindos do efeito combinado de muitas ações individuais. ${ }^{22}$

Por fim, o que se quer dizer exatamente com "bem comum" na mão invisível? Primeiramente, cabe notar que se trata de bem comum econômico, e não bem comum num sentido mais abrangente - mais um fator de inserção de Smith na revolução de valores apontada por Bianchi (1988), Cardoso (2002) e Hirschman (1977). Na WN o bem comum se realiza, como já observamos, por suave agregação da realização dos interesses individuais, diferentemente do que ocorre na TMS. Nesta o bem comum, definido como o sustento alimentar de todos (e não como o crescimento da renda,

21 Elster (1984) destaca não apenas a possibilidade de bloqueamento recíproco, como principalmente a possibilidade de um "espiral vicioso de comportamento autoderrotável". Esta concepção de contrafinalidade será retomada adiante.

22 Já na TMS, é a ação de um único indivíduo (o proprietário de terras) que leva ao bem comum. Contudo, como observamos, este caso distancia-se do argumento da WN em diversos aspectos, aproximando-se mais de Mandeville em termos de paradoxo. 
como na $W N$ ), ocorre não como efeito direto por agregação, mas praticamente como efeito colateral da luxúria de um único indivíduo. ${ }^{23}$

\section{À GUISA DE CONCLUSÃO: ORDEM NATURAL, OTIMISMO E INSTITUIÇÕES}

Pretendemos, nesta conclusão, retomar alguns pontos que foram levantados ao longo do texto, que reclamam tratamento mais detido. O tema unificador será a ambivalência smithiana com respeito ao progresso econômico, lucidamente apontada por Hirschman (1977). Prosseguimos, portanto, em nossa ambiciosa empreitada de contribuir para a "descanonização" de Smith, ao explorar o jogo entre otimismo e ceticismo em sua obra.

Cardoso (2002) argumenta em favor de uma "conexão intima entre a formação da economia politica como a ciência que buscava explicar a lógica pela qual os mercados operavam, e o entendimento deste mesmo mercado como a ordem natural das coisas." (Grifos nossos). Como já aludido, o processo em que se insere a formação da economia política é longo e complexo, com dois movimentos importantes subjacentes: a emergência da sociedade de mercado e industrial, no plano histórico, e a secularização da ciência natural e da ciência do homem, no plano intelectual. Neste segundo plano, observase que as correntes da história natural e da filosofia do direito natural sugeriram à economia política nascente o esforço de explicar aquela nova realidade concreta que surgia à luz de uma concepção pela qual a lógica da natureza humana e do processo social poderiam ser descobertos. Em outras palavras:

"A existência de leis naturais universalmente aceitas que são inerentes à natureza humana, [e] a crença em uma ordem natural espontânea, harmoniosa e auto-reguladora, foram todos elementos cruciais para a explicação da ordem econômica do mercado e foram conseqüentemente inseparáveis do discurso da ciência que procurava elucidar os mecanismos aos quais esta mesma ordem estava sujeita." (Ibid).

É curioso, como se pode perceber, que a metafísica cristã tenha sido substituída por uma metafísica da lei natural. Esta nova metafísica guarda, ainda, como não se pode deixar de notar, elevada carga de otimismo a priori. Ora, as referências de Smith ao "grande sistema do universo", bem como a um "sistema de liberdade natural", inserem-no em cheio dentro desta interpretação. Resta, contudo, o "ônus doutrinário",

23 Estas observações mostram que a mão invisível na TMS, embora constitua uma subcategoria interessante de consequiências não intencionais e ofereça resposta de tonalidade mandevilliana à questão de $\mathrm{A}$. Sen sobre a conciliação do egoísmo com o bem comum, pouco vale enquanto resposta às inquietações de Coase, Arrow e Hahn a respeito de uma economia mercantil descentralizada. 
de que fala Cardoso, associado à explicação do vínculo entre o auto-interesse e a realização do bem-estar social; e, como já apontamos, é precisamente Smith quem trata de resolver o problema, ao "explicar a relação entre auto-interesse e bem-estar social endogenamente." (Ibid, grifo nosso).

A principal lição que fica desta discussão é a seguinte: Smith certamente partilhava da concepção de uma natureza humana com princípios a serem investigados, assim como há em seu pensamento uma idéia clara de ordem natural, cuja metafísica é no todo benfazeja. Dentro desta, Smith mostra o vínculo causal concreto entre o auto-interesse individual e o bem-estar geral, de modo que sua metafísica benfazeja prescinde, de fato, da intervenção divina para ser atingida. Não é Júpiter, não é um ditador benevolente, não é nenhum mecanismo indecifrável, é a própria ordem natural que propicia, aqui e ali, resultados socialmente desejáveis.

Mas Smith não é Pangloss, como já dissemos. Não será ingênuo a ponto de crer que o final feliz é inexorável, e que a simples busca do auto-interesse levará inevitavelmente ao bem de todos. Como afirma mais uma vez Cardoso,

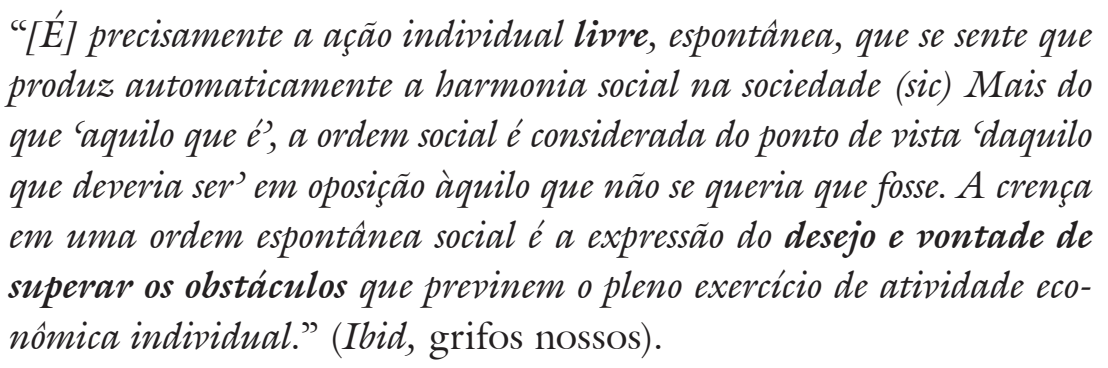

Ora, boa parte da $W N$ (ao menos o livro IV inteiro, no qual aparece a mão invisível) tem como alvo certo o Mercantilismo, cujas "restrições e privilégios injustos" Smith sempre reprovava. Sua ordem natural, portanto, não é inevitável e, para que seus efeitos harmoniosos pudessem ser percebidos haveria a necessidade de se superar estes obstáculos, que Smith acusa com tanta veemência em diversas e conhecidas passagens da $W N$.

Este ponto nos leva a outro, a que aludimos há pouco, sobre o papel das instituições no pensamento de Smith. Em artigo inspirador, Rosenberg (1960) aponta este aspecto relativamente pouco notado do pensamento de Smith:

"Um tema negligenciado que corre através de virtualmente toda a Riqueza das Nações é a tentativa de Smith de definir, em temos muito especificos, os detalhes de uma estrutura institucional que melhor harmonizará a busca do individuo de seus interesses egoistas com os interesses mais amplos da sociedade. (...) É a função de arranjos institucionais 
cortar todas as avenidas (e elas são muitas) ao longo das quais a riqueza pode ser perseguida sem contribuir para o bem-estar da sociedade. Tal objetivo na prática requer um balanceamento cuidadoso de incentivo, de provisão de oportunidade para se aumentar a renda, contra a necessidade de minimizar as oportunidades para abuso, i.e., possibilidades de se incrementar a renda de maneira anti-social." (Rosenberg, 1960, p. 559-60, grifos nossos).

Dito de outra forma, a realização dos resultados benéficos ou perversos da busca individual do auto-interesse dependerá do conjunto de restrições institucionais sob o qual os indivíduos operam. Embora simples, esta observação é crucial, pois Smith também reconhece que a busca predatória do auto-interesse num contexto de incentivos perversos pode levar a resultados de penúria social - o que reflete, incidentalmente, uma ocorrência da "contrafinalidade" sartriana, que apontamos anteriormente. Com efeito, o leitor de Smith encontrará diversos casos nos quais a busca predatória do interesse privado leva a resultados sociais lamentáveis, como é o caso da Espanha e de Portugal naquele tempo. (WN IV.vii.c.61). Ao contrastar a conduta dos "lordes magnificentes" de Lisboa e Cádiz com a dos "burgueses atentos e parcimoniosos" de Amsterdã, Smith não deixa de notar como a conduta de cada grupo é afetada pelas oportunidades (institucionais) a eles abertas, e como os resultados sociais (mendicância ou prosperidade) dependem amplamente destes mesmos fatores. $\mathrm{O}$ argumento institucional, em suma, não apenas indica a não inevitabilidade da mão invisível, como também seu caráter contingente ao ambiente institucional.

De toda a forma, ao contrário de Lord Robbins (1952), não devemos rechaçar a presença de uma Harmonielehre na economia clássica, ou particularmente em Smith. Não obstante, ressaltamos a importância de que este otimismo cósmico, tão afeito ao iluminismo, deve ser ao menos qualificado, tratando-se do pensamento de Smith. Um importante fator de qualificação diz respeito à mencionada importância de fatores institucionais que efetivamente liberem o caminho para que a ordem natural faça se sentir em seus efeitos benéficos.

Outro fator de qualificação do otimismo de Smith diz respeito a seu sentimento de ambivalência diante do progresso econômico. (Hirschman, 1977). Smith nutria visão cáustica e negativa dos poderosos de seu tempo, tanto dos políticos como dos homens de negócios que se beneficiavam do statu quo, e por estas razões era muito cético quanto à possibilidade de que o livre comércio que propunha pudesse realmente ser estabalecido:

"Esperar, de fato, que a liberdade de comércio devesse ser inteiramente restaurada na Grã-Bretanba, é tão absurdo quanto esperar que uma 
Oceana ou Utopia devessem ser estabelecidas ali. Não apenas os preconceitos do público, mas o que é muito mais inconquistável, os interesses privados de muitos individuos, irresistivelmente se opõem a isto." (WN IV.ii.43).

É curioso notar que os homens de negócios, heróis da $W N$ em tantas ocasiões, sejam em outras passagens objeto de comentários corrosivos por parte do autor, para quem tal classe de indivíduos estava sempre a "conspirar contra o público" com vistas à obtenção de maiores vantagens. ${ }^{24}$ Da mesma forma, a divisão do trabalho, tão entusiasticamente exposta como fonte da produtividade e da riqueza das nações no início da $W N$ recebe, ao final da mesma, tratamento lúgubre em virtude de seus efeitos deletérios sobre as capacidades intelectuais ou mesmo morais das pessoas, que passam a vida a realizar, repetitivamente, "uma ou duas operaçôes simples" apenas. (WN V.i.f.50).

Smith certamente é um homem de seu tempo, e há em seu pensamento uma tonalidade liberal, burguesa e individualista, além de uma visão de mundo grosso modo positiva com relação ao capitalismo - com a ressalva das qualificaçóes que acabamos de fazer. Seu ceticismo moderado, contudo, não desmancha sua visão de uma ordem natural harmônica, e tampouco o conduz a ocupar o mesmo barco de autores como Marx, Keynes e Schumpeter que, tendo vivido em outra época histórica, ressaltaram o caráter inerentemente instável da economia capitalista.

\section{REFERÊNCIAS BIBLIOGRÁFICAS}

Arida, Pérsio [1984]. A história do pensamento econômico como teoria e retórica. In: Rego, J. M. (org.), Retórica na economia. Editora 34, 1996.

Arrow, Kenneth; Hahn, Frank. General competitive analysis. Holden Day, Inc., 1971.

Belluzzo, Luiz G. [1980]. Valor e capitalismo. Um ensaio sobre a economia capitalista. IE/Unicamp, 1998.

Bianchi, Ana Maria. A pré-história da economia: de Maquiavel a Adam Smith. São Paulo: Hucitec, 1988.

Bianchi, Ana Maria; Nunes, Rubens. Ainda sobre os conceitos de paradigma e cânon como instrumentos de reconstrução da história do pensamento econômico. Econômica, v. 4, n. 2, 2002.

Brown, Vivienne. Adam Smith's discourse - Canonicity, commerce and conscience. Routledge, 1994.

24 Rosenberg (1979) dá uma lista extensa de tais passagens encontradas na $W N$. 
Cardoso, José Luís. Natural law, natural history and the foundations of political economy. In: Davis, Marciano, Runde (eds.), The Elgar companion to economics and philosophy. 2002.

Cerqueira, Hugo. Para ler Adam Smith: novas abordagens. Texto para Discussão n. 183, Cedeplar/UFMG, 2003.

Coase, Ronald. The wealth of nations. Economic Inquiry, v. 15, julho de 1977.

Elster, Jon. Making sense of Marx. Cambridge University Press, 1984.

Fonseca, E. Giannetti da. Vicios privados, benefícios públicos? A ética na riqueza das nações. São Paulo: Cia das Letras, 1993.

Ganem, Angela. Adam Smith e a explicação do mercado como ordem social: uma abordagem histórico-filosófica. Revista Economia Contemporânea, v. 4, n. 2, p. 9-36, jul/dez. 2000.

Hayek, Friedrich. The results of human action but not of human design. In: Studies in philosophy, politics and economics. The University of Chicago Press, 1967.

Henderson, W. The use of metaphor in economics. In: Backhouse (ed.), New directions in economic methodology. Routledge, 1994.

Hirschman, A. As paixóes e os interesses: argumentos políticos a favor do capitalismo antes do seu triunfo. Ed. Record, 1977.

. A retórica da intransigência. São Paulo: Cia. das Letras, 1992.

Hollander, S. Adam Smith and the self-interest axiom. Journal of Law and Economics, v. 20, n. 1, 1977.

Macfie, Alec. The invisible hand of Jupiter. Journal of the History of Ideas, v. 32, n. 4, p. 595-599, 1971.

Merton, Robert. The unanticipated consequences of purposive social action. American Sociological Review, v. 1, n. 6, 1936.

North, Douglass. Institutions, institutional change and economic performance. CUP, 1990.

Nozick, Robert. Invisible-hand explanations. American Economic Review, 84, p. 314318, 1994.

Nunes, Rubens. A articulação do paradigma clássico - Valor e mercado no pensamento econômico (1803-1836). 1995. Dissertação (Mestrado), IPE/USP. São Paulo.

Raphael, D. D.; Macfie, A. L. Introduction. In: Smith, Adam, The theory of moral sentiments. Oxford University Press, 1976.

Robbins, Lionel. [1952]. Teoria da política econômica. São Paulo: Ibrasa e Edusp, 1972.

Rosenberg, Nathan. Some institutional aspects of the wealth of nations. Journal of Political Economy, v. 18, n. 6, p. 557-570, 1960. 
. Adam Smith and laissez-faire revisited. In: O'Driscoll (ed.), Adam Smith and modern political economy. Iowa University Press, 1979.

Rothschild, Emma. Adam Smith and the invisible hand. American Economic Review 84, 1994.

Santos, Antonio T. Loureiro. Adam Smith: comportamento econômico e resultados sociais. Trabalho de conclusão do curso de graduação em Economia, FEA/USP, 2002.

Sen, Amartya. [1987]. Sobre ética e economia. São Paulo: Cia. das Letras, 1999.

. [1979]. Rational fools: a critique of the behavioural foundations of economic theory. In: Sen, A., Choice, welfare and measurement, 1982.

Skinner, Andrew. Adam Smith: ethics and self-love. In: Jones, P.; Skinner, A. (orgs.), Adam Smith reviewed. Edinburgh University Press, 1992.

Smith, Adam. [1759]. The theory of moral sentiments. The Glasgow Edition of the Works and Correspondence of Adam Smith, Oxford University Press, 1976.

. [1776]. An inquiry into the nature and the causes of the wealth of nations. The Glasgow Edition of the Works and Correspondence of Adam Smith, Oxford University Press, 1976.

. [1795]. The principles which lead and direct philosophical enquiries; illustrated by the history of astronomy. In: Essays on philosophical subjects. The Glasgow Edition of the Works and Correspondence of Adam Smith, Oxford University Press, 1976. 